\title{
Study of Possibilities of Using Special Types of Building and Demolition Waste in Civil Engineering
}

\author{
Rostislav Drochytka1*, Zdeněk Dufek, Magdaléna Michalčíková1, Jakub Hodul ${ }^{1}$ \\ 1 Institute of Technology of Building Materials and Components, Faculty of Civil Engineering, Brno University of Technology, \\ Veveri 95, 60200 Brno, Czech Republic \\ * Corresponding author, e-mail: drochytka.r@fce.vutbr.cz
}

Received: 15 October 2019, Accepted: 10 December 2019, Published online: 15 January 2020

\begin{abstract}
Construction and demolition waste makes up a substantial part of all waste produced in Europe. Its impact on the environment may be relatively small, but it exists in large amounts and holds many options of re-use. This is why it remains a frequently discussed topic of European policy. As part of circular economy, the European Commission has already proposed new goals and strategies for existing types of waste. However, they are not entirely clear on the usage of new kinds of building and demolition waste, as they are yet to be specified by existing legislation. This paper discusses new kinds of building and demolition waste and the basic principles (new technology) of their use. The possibilities of utilizing new kinds of waste are based on a multicriteria optimization calculation, specifying each material and proposing ways of its further use. Recent findings can expand the choice of new uses of construction and demolition waste and reduce their impact on the environment (less waste, better properties and more effective processing, reducing transportation needs, maximizing re-use and recycling).
\end{abstract}

Keywords

construction and demolition waste, energy by-products, multicriteria optimization calculation, environment, re-use

\section{Introduction}

The key legislation governing construction and demolition waste (CDW) is the general Directive on waste [1], which defines basic terms and definitions that pertain to waste handling. It sets a goal for member states to meet the $70 \%$ recycling target by 2020 . If the average European recycling rate growth per year keeps being just $1 \%$ then not only by 2040 will the target be met [2-4].

Other noteworthy documents are the Circular Economy Package [5], which contains revised legal proposals on waste, and the Circular Economy Action Plan (CEAP) [6], which is intended to prompt Europe to transition to circular economy $[2,3,7,8]$. This plan focuses on "closing the loop", i.e. a transition from a linear economy to a circular one. Bovea and Powell [9], and Coelho and Brito [10] stated that more so now than any time in the past, this action plan emphasizes by-products and the value of waste at the end of a material's service by re-use and recycling as a central part of circular economy.

Better usage of construction waste is also addressed in the Construction Sector Competitiveness strategy of 2020
$[2,11]$, as well as in a communication from the commission to the European parliament on resource efficiency opportunities in the building sector [12]. Other worthy mentions are also eco-management and audit scheme on best environmental management practice in waste management (and thus also construction and demolition waste) and civil engineering $[4,9,13]$.

\section{Basic EU statistics}

A study by Eurostat and the European Commission [14] shows that waste production statistics within the EU depend very much on how civil engineering is viewed as an industry. If demolition is included, the total amount of waste produced in 2014 was 859 million tons [15]. However, if we only consider mineral waste, metals, wood, household waste and other municipal waste (i.e. everything except soil, etc.), the total construction and demolition waste was only 337 million tones. A dominant parts of this are mineral wastes, making up $87 \%$. Fig. 1 shows this data in detail. 


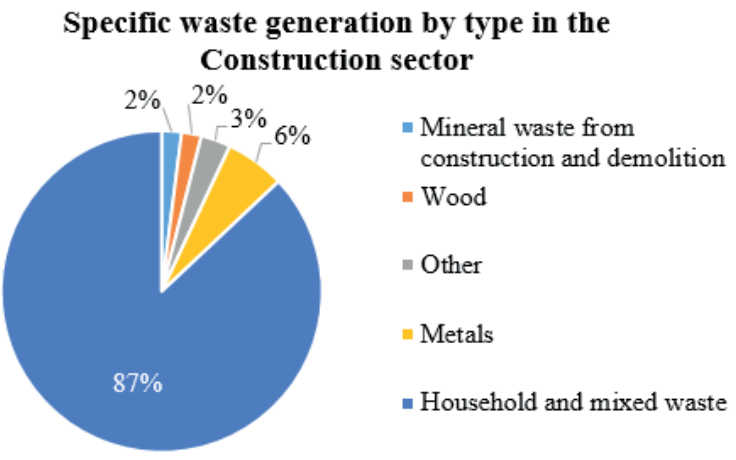

Fig. 1 Overview of CDW production by type in the EU in 2014 (excluding soil and dredging spoils) [14]

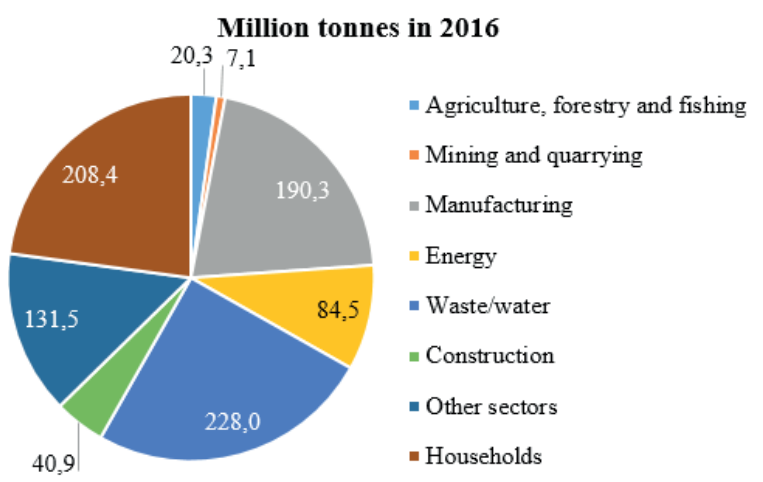

Fig. 2 Overview of CDW production in the EU in 2016 [16]

The main sources of non-mineral waste in the EU in 2016 are shown in Fig. 2. The total amount of waste produced in the EU that year was 2.533 million tons (including mineral waste). Construction waste made up $36.4 \%$.

CEAP considers building waste recycling to be key for achieving the goals of circular economy [2, 7, 15]. Construction and demolition waste is one of the largest categories of waste in Europe, estimated at one third of all waste produced [14, 17].

At the same time construction and demolition waste has great potential for the manufacture of recycled materials. Naturally, it would take substantial investments into the recycling infrastructure if the volume is to be increased. A study by the European Commission [14] states that Europe currently lacks the necessary recycling infrastructure to sustain an increase in construction waste recycling to its maximum. Bakchan and Faust [18] declare in their study that it should also be noted that the building industry has the potential to re-use waste from other industries. Later sections of this paper describe a new multi criteria calculation that explores possibilities of the re-use of certain kinds of waste, mainly construction and demolition waste and energy by-products, which are being produced in large quantities (see Table 1). These energy by-products include mainly fly ash (FBC - Fluidized bed combustion fly ash, high-temperature fly ash, bottom ash from fluidized bed combustion etc.) and slag.

3 Multicriteria optimization of using new types of waste Research and development focused on using construction and demolition waste and energy by-products in civil engineering is currently seeing a rapid surge [7, 18].

Coelho and Brito [10] stated that the reasons are both financial and environmental. A clear environmental benefit is the reduction of energy by-products stockpiling by using them in the manufacture of quality materials that further reduce the need to exploit natural resources. According the study of Neto et al. [19], in economic terms, this brings significant savings in storage costs for by-products originators. Concerning the use of construction and demolition waste and energy by-products in civil engineering, it is important to remember, besides the environmental and financial concerns, that the new materials have to meet the technical requirements prescribed by standards or other legal documents. This may sometimes cause issues. When construction and demolition waste and energy by-products fail to meet some of the requirements, they need to be modified (mechanically, chemically, physically, etc.). This modification or treatment always comes at the cost of higher expenditure or harm to the environment.

Concerning the usage of construction and demolition waste and energy by-products the EU has directives and harmonized standards that clearly describe conditions under which each kind of waste can be re-used in the construction industry. Nowadays, however, there are new kinds of construction and demolition waste emerging, for which there is no directive or harmonized standard. Specifically, this concerns some types of waste glass, filter fly ash, bottom ash, slag, waste perlite, etc. (see Table 1). In order to find potential uses for these, their properties and criteria must be specified [7, 18].

Therefore, the goal of this paper is to design and prepare an optimization process to specify the new (and some existing) types of construction and demolition waste and energy by-products so as to determine clear criteria based on which these wastes could be used in the future. This was achieved by creating an optimizing multi criteria calculation, which was based on the main viability criteria governing the usage of each type of waste. The calculation process works with several criteria, all of which are discussed later in the text. Emphasis was put on the degree of pretreatment, difficulty of pretreatment, availability, cumulative amount, 
Table 1 Overview of currently used as well as new kinds of CDW and EBP including their specifications (criteria and possibilities)

\begin{tabular}{|c|c|c|c|c|c|c|c|c|}
\hline 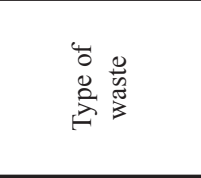 & $\stackrel{n}{\overrightarrow{\widetilde{E}}}$ & 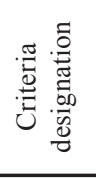 & 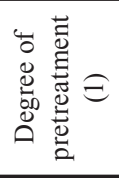 & 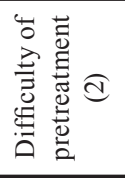 & 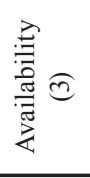 & 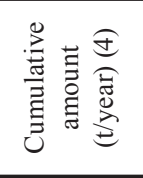 & 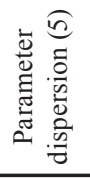 & 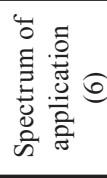 \\
\hline \multirow{6}{*}{ Waste glass } & Container (soda-lime) (Fig. 3 a)) & A & 2 & 2 & 2 & 60000 & 3 & 8 \\
\hline & Car glass (Fig. 3 b)) & $\mathrm{B}$ & 4 & 3 & 2 & 6000 & 2 & 5 \\
\hline & Sandblasting glass beads (Fig. 3 c)) & $\mathrm{C}$ & 2 & 1 & 3 & 2000 & 1 & 4 \\
\hline & Simax borosilicate glass (Fig. 3 d)) & $\mathrm{D}$ & 2 & 3 & 2 & 6000 & 1 & 4 \\
\hline & QS solar panel glass (Fig. 3 e)) & $\mathrm{E}$ & 3 & 2 & 1 & 10000 & 2 & 8 \\
\hline & CRT screens & $\mathrm{F}$ & 3 & 4 & 2 & 10000 & 2 & 3 \\
\hline \multirow[t]{2}{*}{ Filter fly ash } & $\begin{array}{l}\text { High-temperature } \\
\quad \text { (Fig. } 3 \text { f)) }\end{array}$ & G & 0 & 0 & 1 & 6000000 & 2 & 9 \\
\hline & FBC (Fig. 3 g)) & $\mathrm{H}$ & 0 & 0 & 1 & 9000000 & 2 & 7 \\
\hline \multirow{3}{*}{ Bottom ash } & High-temperature (Fig. 3 h)) & I & 2 & 1 & 1 & 600000 & 2 & 6 \\
\hline & FBC (Fig. 3 i)) & $\mathrm{J}$ & 1 & 1 & 1 & 600000 & 2 & 5 \\
\hline & Biomass (Fig. 3 j)) & K & 1 & 1 & 3 & 200000 & 3 & 4 \\
\hline \multirow[t]{2}{*}{ Slag } & $\begin{array}{l}\text { Blast-furnace } \\
\text { (Fig. } 3 \mathrm{k} \text { )) }\end{array}$ & $\mathrm{L}$ & 2 & 2 & 2 & 100000 & 2 & 5 \\
\hline & Steelworks (Fig. 3 1)) & M & 2 & 2 & 2 & 70000 & 2 & 3 \\
\hline Waste perlite & $\begin{array}{c}\text { Perlite 150, Agro Perlite, Perlite } \\
\text { 100F A, Perlite 100F B } \\
\text { (Fig. } 3 \text { m)) }\end{array}$ & $\mathrm{N}$ & 1 & 1 & 2 & 20800 & 2 & 5 \\
\hline $\begin{array}{l}\text { Waste casting } \\
\text { sand }\end{array}$ & $\begin{array}{l}\text { Contains some bentonite, liquid } \\
\text { glass, clay, graphite, residual } \\
\text { resins, and coal dust (Fig. } 3 \text { n)) }\end{array}$ & $\mathrm{O}$ & 2 & 2 & 2 & 5000 & 3 & 6 \\
\hline Waste plastics & $\begin{array}{l}\text { PET bottles, PET sheets, LDPE } \\
\text { packaging (Fig. } 3 \text { o)) }\end{array}$ & $\mathrm{P}$ & 5 & 4 & 1 & 300 & 2 & 4 \\
\hline $\begin{array}{l}\text { Polyester (PES) } \\
\text { fiber }\end{array}$ & $\begin{array}{l}\text { Polyester fiber from waterproofing } \\
\text { material production (Fig. } 3 \text { p)) }\end{array}$ & Q & 3 & 3 & 4 & 200 & 3 & 4 \\
\hline $\begin{array}{l}\text { Recycled } \\
\text { concrete }\end{array}$ & Fraction $0-63 \mathrm{~mm}$ (Fig. $3 \mathrm{q})$ ) & $\mathrm{R}$ & 1 & 2 & 1 & 50000 & 2 & 9 \\
\hline $\begin{array}{l}\text { Waste from } \\
\text { mineral wool } \\
\text { board insulation } \\
\text { production } \\
\text { (WMI) }\end{array}$ & $\begin{array}{l}\text { A high content of recycled glass } \\
(>80 \%) \text {, it gathers underneath the } \\
\text { spinner before the curing chamber } \\
\text { and thus do not contain any } \\
\text { organic components (Fig. } 3 \mathrm{r}) \text { ) }\end{array}$ & $\mathrm{S}$ & 0 & 0 & 2 & 5000 & 1 & 5 \\
\hline $\begin{array}{l}\text { Granulated car } \\
\text { tires }\end{array}$ & $\begin{array}{l}\text { Particulate from shredded tires } \\
\text { (Fig. } 3 \mathrm{~s}) \text { ) }\end{array}$ & $\mathrm{T}$ & 2 & 2 & 1 & 10000 & 1 & 3 \\
\hline $\begin{array}{l}\text { Waste } \\
\text { polystyrene } \\
\text { (PS) }\end{array}$ & $\begin{array}{l}\text { Decommissioned façade insulation } \\
\text { boards from expanded PS of } \\
\text { varying thickness (Fig. } 3 \mathrm{t} \text { )) }\end{array}$ & $\mathrm{U}$ & 2 & 2 & 1 & 10000 & 1 & 4 \\
\hline
\end{tabular}

parameter dispersion, and spectrum of application. These parameters were determined by subjective evaluation based on the requirements of the industry and existing legislation.

\subsection{Criteria considered in the optimizing calculation}

In order to perform the multi criteria calculation, it was necessary to first select criteria before progressing to the next steps of the calculation, which then determined the most suitable construction and demolition waste and energy by-products for use in civil engineering. Table 1 below lists the criteria and their associated weight.

The data presented in Table 1 are based on the optimization calculation methodology. The selection of specific values was made regarding to the current situation of the waste management of the construction and demolition waste (CDW) and the energy by-products (EBP) within the European Union (EU). In the case of cumulative amount, the values were focused on the Czech Republic. 


\subsubsection{Degree of pretreatment}

The degree of construction and demolition waste pretreatment means the number of steps a raw material must undergo to be finally useable in a building material. The pretreatment steps can be defined as follows.

Drying - a pretreatment necessary for damp or wet wastes, or solutions to be used in polymers. Drying may also serve to determine water content if required. Drying is typically performed at a temperature of $103 \pm 2{ }^{\circ} \mathrm{C}$, during which the material should be uniformly distributed in the correct container in order to be properly dried.

Removing coarse impurities - once dried, some materials need to have their coarse impurities removed in order to become homogeneous.

Removing unwanted parts - some kinds of waste glass, such as car glass or glass from old solar panels, are reinforced by a layer of polymer, which needs to be removed by placing the composite in a ball mill or a specialized crusher for several minutes.

Milling - once a relatively homogeneous material is obtained, it undergoes the next pretreatment, which is milling. The milling time and type of mill depend both on the type of by-product and requirements for final fineness. Larger amounts can be easily milled in carbide ball mills. Smaller amounts are better milled in planetary or vibration mills.

Adjusting particle size - if the waste material is to be used as filler/aggregate in polymer concrete or in Portlandcement concrete, it must be adjusted to possess the required particle size distribution. Sieves of different size can be used for this purpose.

Glass alkalization - when used in concrete.

Depending on the number of pretreatment steps, every waste is assigned a value of $0-5$, where 1 signifies only one step and 5 represents five. A 0 means that, for the given purpose, the material requires no pretreatment at all. Such material is, for instance, fly ash in concrete.

\subsubsection{Difficulty of pretreatment}

The difficulty of construction and demolition waste pretreatment is another important criterion when choosing a suitable waste to use in building materials. It strongly depends on the waste's consistency and parameters such as hardness and leaching behavior. Difficulty of pretreatment can be understood as the amount of energy (converted to costs) consumed during the entire treatment process. Based on the difficulty, a waste can be assigned a value from 1 to 5 , where 1 is the lowest difficulty and 5 is the highest, i.e. technologically demanding, more expensive, and thus less viable.

\subsubsection{Availability}

Not every construction and demolition waste is produced or stockpiled near the place of its further use. This is why the criterion of availability has to be included in the calculation. Some kinds of waste are only produced at one location in the country, or even the entire EU. The need to transport the waste over several thousand kilometers then makes it much less viable. Moreover, the transport of construction and demolition waste and energy by-products over long distances often brings associated issues, such as carbon emissions, noise, or traffic accidents, which may outweigh the overall benefit of the recycling.

Efficient logistics is therefore a major factor, which may be very useful to the re-use of waste. When making a decision about transportation, the purchaser must consider cost, time, and the reliability of every transport means or their combination. The decision is also affected by roadway/railway and transshipment capacity and costs related to capital employed in the goods. Concerning the costs connected with tied-up capital (or the perceived value of time) the problem is as follows: the longer it takes to deliver the goods, the later the customer is going to pay, and the longer the seller's money remains tied-up. By analogy, this applies to raw materials as well. The more time they spend on the way to the factory, the more the manufacturer has to stockpile and tie their financial means in them. Capital financing of the stockpiled material or manufactured goods, whether from the company's own means or from an external source, carries with its additional expenses, such as interest or opportunity costs. This forces businesses to keep their stockpiles as low as possible. The general trend is that commodities with a high price by weight are better transported by faster means, i.e. by air or cargo truck. On the other hand, cheaper commodities are better suited for transport by railway or ship. Terms of delivery also enter into the equation, as does the minimum or maximum size of the lot delivered. There may even be situations when a customer chooses the slower transport by boat and use the ship as a floating warehouse of sorts. The reason can be, for instance, limited storage capacity at the manufacturing plant where the material is processed. An advantage of the logistics of construction and demolition waste and energy by-products is that their value per weight is very low or near zero. The seller considers them waste and would otherwise have to pay for their disposal. This makes these commodities very suitable for transport by railway or boat. Given the cargo capacity of river boats 
(provided the river network is included in the logistic system) significant savings can be made both in terms of monetary costs and in terms of reducing associated negative externalities.

Given the above, there is a need for boundaries that would determine whether the use of a secondary raw material is viable in terms of availability or not. Filter fly ash and waste glass should not suffer any problems with availability; however, waste perlite is at some risk. Based on these considerations, an evaluation scale of 1-5 was proposed, where 1 is the most available raw material and 5 is the least.

\subsubsection{Cumulative amount}

Different construction and demolition waste and energy by-products accumulate in different amounts. For instance, the cumulative amount of energy by-products depends mainly on the quality of feedstock, effectiveness of the facility that produces the primary raw materials, and the annual product yield. The cumulative amount of energy by-products and construction and demolition waste may vary depending on demand, and it is therefore only possible use current data and not predict the situation for future years. The data was taken from publicly accessible information from the producers of the energy by-products and the construction and demolition waste. Some of this waste is currently broadly used in civil engineering, but some is still being stockpiled because it has no other use and is considered waste. The optimization of suitable construction and demolition waste puts emphasis on its annual production, where the highest demand should be after waste accumulated at a yearly amount of 10000 tons or more. The cumulative annual amount of waste only concerns the Czech Republic. However, almost all the construction and demolition waste listed in the Table 1 is produced throughout the EU as well as the world. An example can be filter fly ash or waste glass, because coal-burning thermal power plants exist all over the world, and every country uses glass, whether container glass or other, such as solar panels. Table 1 lists and evaluates the multi criteria and shows the cumulative amount in tons per year in the Czech Republic.

\subsubsection{Parameter dispersion}

Every construction and demolition waste (CDW) and energy by-products (EBP) which is useable in civil engineering can be characterized by various parameters. They are identified based mainly on the level of hazard they present (e.g. toxicity) and their physical and mechanical parameters. This typically entails determining the chemical composition, particle size, bulk density, specific surface area, and water absorption. Broader identification is also possible, which tests the $\mathrm{pH}$, loss on ignition, leaching behavior, and other properties. Individual wastes need not always be equally homogeneous. There may be variations between individual samples, whether in chemical composition or granulometry. An excellent example is filter fly ash, where the chemical composition and granulometry may vary depending on the type and source of coal being burned, and nowadays also the amount and type of denitrification agent sprayed in the combustion chamber. Depending on the degree of these and other parameters, every construction and demolition waste can be evaluated on a 1-5 scale, where the lowest value means the highest-quality waste in terms of parameter homogeneity and the highest value represents substantial dispersion in properties between individual samples, preventing a consistent determination of parameters.

\subsubsection{Spectrum of application}

Not all construction and demolition waste and energy by-products can be used in every building material or as a replacement of an existing one. However, when choosing the correct usage of the waste, the broadest spectrum of application needs to be considered. The Table 1 assigns a "spectrum of application" to each waste, showing areas where the waste can be safely used. These applications are either already being implemented in practice or have been thoroughly tested in a laboratory based on extensive research. The spectrum of application depends first and foremost on the properties of the waste and their variability. Similarly, to the previous cases the spectrum of application is expressed by a value of $1-10$ where 1 is narrowest and 10 the broadest spectrum for the given construction and demolition waste or energy by-products. This value also includes pretreatments, which means if the waste is pre-treated in some way to improve its properties, this will affect the spectrum. For example, waste glass, which can be used as an aggregate in its coarser fraction, could be milled to a particle size of less than $0.063 \mathrm{~mm}$ and replace silica powder as a filler in paints. The photos of specific types of waste to be optimized are shown in Fig. 3.

\subsection{Determining the weight of each waste criterion}

Once the criteria were identified (Table 1) it was possible to continue with the next, and the most important, step of the multi criteria calculation; i.e. determining their weight. Every property described by a criterion has different 

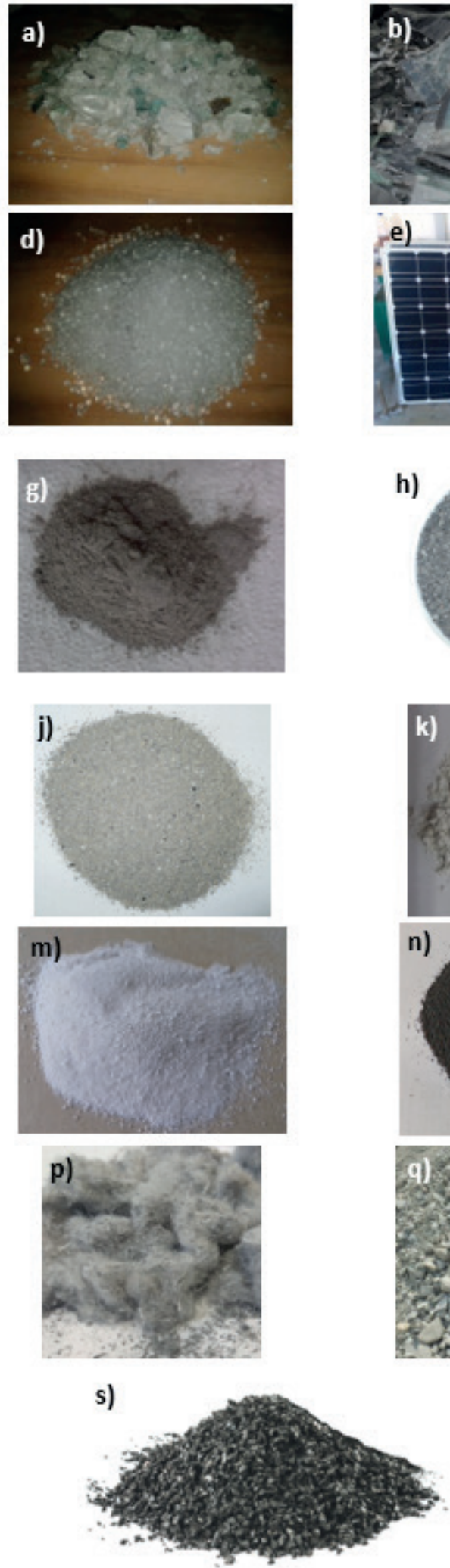

h)
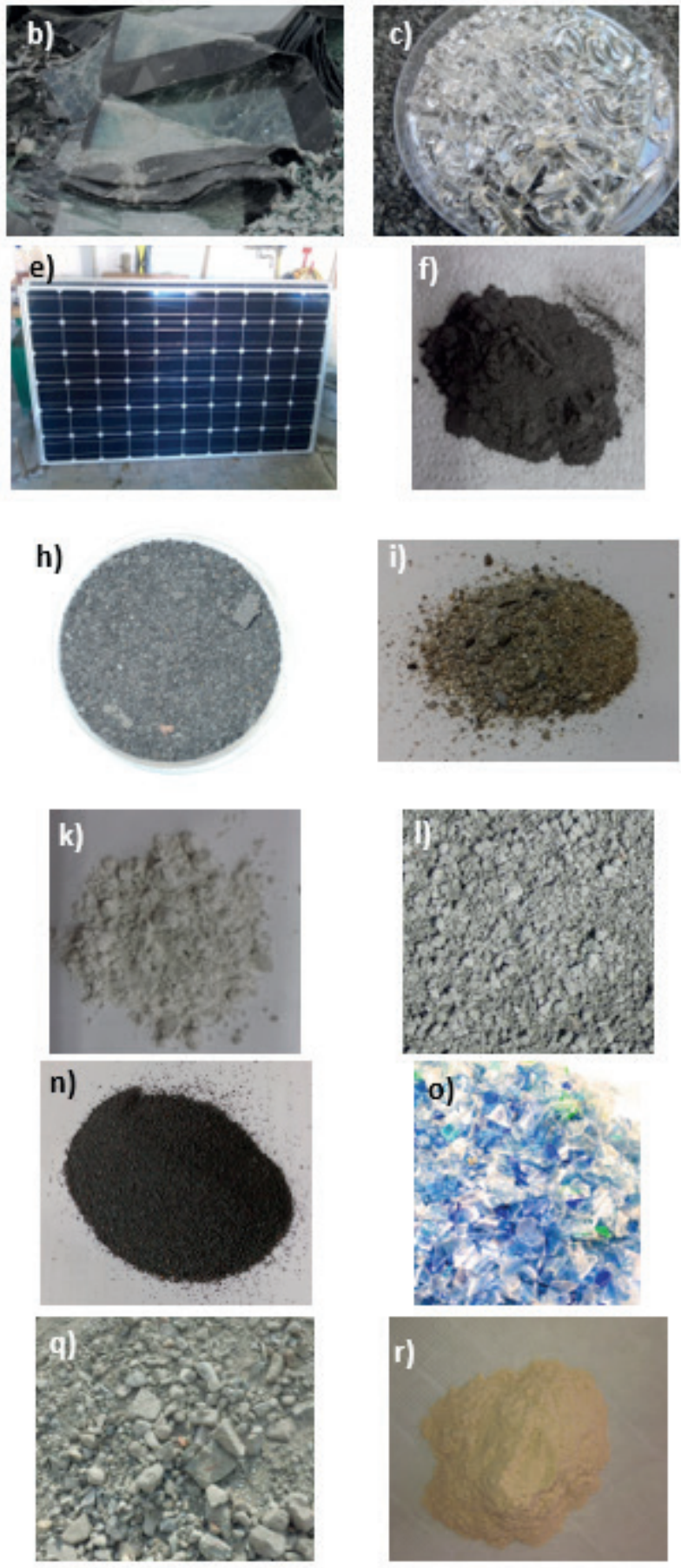

r)

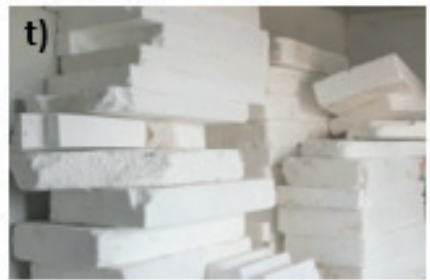

Fig. 3 The specific types of waste to be optimized: a) container (soda-lime) waste glass, b) car glass, c) sandblasting glass beads, d) Simax borosilicate glass, e) QS solar panel glass, f) high-temperature fly ash, g) fluidized bed combustion fly ash (FBC), h) bottom ash from hightemperature combustion, i) bottom ash from fluidized bed combustion (FBC), j) biomass bottom ash, k) blast-furnace slag, 1) steelworks slag, $\mathrm{m}$ ) waste perlite, $\mathrm{n}$ ) waste casting sand, o) waste plastics, p) polyester fiber from waterproofing material production, q) recycled concrete fraction 0-63, r) waste from mineral wool board insulation production (WMI), s) granulated car tires, t) waste polystyrene (PS) 
weight. These criteria were used to evaluate the properties and determine which one is given preference over another. This step was performed subjectively (expert evaluation method). Based on the subjective assessment, each criterion received a score that quantitatively reflected the importance of each one. The more important the property, the higher the score.

A criterion-based decision-making matrix was created from the information in Table 1. It can be described as a finite set of material evaluation variants. The columns of this matrix list criteria (1-6) and the rows show the variants being evaluated (A-U). Each criterion was then marked max. (where a maximum was required) or min. (where a minimum value was required). Maximum values were need for criterion 4 (cumulative amount) and 6 (spectrum of application). Minimum values were required for criterion 1 (degree of pretreatment), 2 (difficulty of pretreatment), 3 (availability), and 5 (parameter dispersion).

The higher a score a criterion received, the more weight it carries. Saaty's matrix was used to express the preference of each criterion (Table 2), ranking them as "strongly preferred", "preferred", or "equal". The individual components of the matrix are defined using Eqs. (1) and (2). The weight of the criteria was determined using Eq. (3).

$$
\begin{aligned}
& S_{i}=\prod_{j=1}^{n} S_{i j}, \\
& R_{i}=\left(S_{i}\right)^{\frac{1}{n}}, \\
& F_{i}=\frac{R_{i}}{\sum_{i=1}^{n} R i},
\end{aligned}
$$

where, $S=\left(S_{i j}\right) \ldots$ Saaty's matrix of pair comparison, where $i, j=1,2,3, \ldots n, f_{i} \ldots$ total criteria weight.

A corresponding verbal assessment:

1 - criteria $i$ and $j$ are equal;

3 - criterion $i$ is slightly preferred over $j$;
5 - criterion $i$ is strongly preferred over $j$;

$7-$ criterion $i$ is very strongly preferred over $j$;

9 - criterion $i$ is absolutely preferred over $j$.

Values 2, 4, 6, 8 are intermediate steps.

The last step of the calculation was to transform the decision matrix into a calculation matrix and complete the calculation. Transformation means converting the criterion weight values to sequences, creating an order of variants and converting these values to dimensionless numbers. This very much depends on the value type of the individual criteria. An expense-type value is such a value which is subject to a minimum requirement. The transformation was performed as follows: The maximum value max. $a_{i j}$ corresponds to the lowest appraisal value (mostly $b_{i j}=0$, see Eq. (4)) and the lowest value min. $a_{i j}$ corresponds to the highest appraisal $\left(b_{i j}=1\right.$, see Eq. (5)). A profit-type value is such a value that is subject to a maximum requirement. This means that the higher a value the criterion reaches, the better appraisal it receives.

$$
\begin{aligned}
& \stackrel{\operatorname{MAX}_{i j}}{\rightarrow}=\frac{a_{i j}-\operatorname{MIN}\left(a_{i}\right)}{\operatorname{MAX}\left(a_{i}\right)-\operatorname{MIN}\left(a_{i}\right)}, \\
& \stackrel{\operatorname{MINb_{ij}}}{\rightarrow}=\frac{\operatorname{MAX}\left(a_{i}\right)-a_{i j}}{\operatorname{MAX}\left(a_{i}\right)-\operatorname{MIN}\left(a_{i}\right)}, \\
& c_{i j}=F_{i} \cdot b_{i j} \cdot 100,
\end{aligned}
$$

where, $b_{i j}$ is the transformed value using Eqs. (4) and (5), $F_{i}$ is the criterion weight.

The outcome of the transformation was an order of viability of material variants $A$ through $U$ and the determination of an optimal variant, a variant with the highest total the products of transformed criteria and weight values in percent (see Eq. (6)). Given the dangers of subjective evaluation, we take into account mainly the larger differences between the totals; smaller differences were considered more or less "equal".

Table 2 Quantitative pair comparison of criteria - Saaty's matrix

\begin{tabular}{lccccccccc}
\hline No. & 1 & 2 & 3 & 4 & 5 & 6 & $S_{i}$ & $R_{i}$ & $F_{i}$ \\
\hline 1 & 1 & 3 & $1 / 3$ & $1 / 3$ & 1 & $1 / 4$ & 0.08333333 & 0.01388889 & 0.000635849 \\
2 & $1 / 3$ & 1 & $1 / 2$ & $1 / 4$ & 1 & $1 / 5$ & 0.00833333 & 0.00138889 & 0.000063585 \\
3 & 3 & 2 & 1 & 1 & 5 & $1 / 3$ & 10.00000000 & 1.66666667 & 0.076301901 \\
4 & $1 / 3$ & 4 & 1 & 1 & $1 / 4$ & $1 / 2$ & 0.16666667 & 0.02777778 & 0.001271698 \\
5 & 1 & 1 & $1 / 5$ & 4 & 1 & 1 & 0.80000000 & 0.13333333 & 0.006104152 \\
6 & 4 & 5 & 3 & 2 & 1 & 1 & 120.0000000 & 20.00000000 & 0.915622814 \\
Total & & & & & & & & 21.84305556 & 1.00000000 \\
\hline
\end{tabular}


The outcome of the multi criteria calculation was a selection of construction and demolition waste and energy by-products for future use in civil engineering. They had the highest total of the products of transformed criteria values, weights and order of viability of all variants. Given the many subjective evaluations, variants with a small difference in the final totals were considered more or less "equal".

Fig. 4 shows a resulting graph of the multi criteria calculation, presenting the choice of the most viable construction and demolition waste and energy by-products for future use in civil engineering. The preferences of each specific waste are in percent. The highest value, as can be seen in Fig. 4, was calculated for filter fly ash (99.65 \%), then recycled concrete $(99.55 \%)$, and waste glass from QS solar panels (84.27\%). The next section presents some non-traditional uses of the best scoring energy by-products and construction and demolition waste.

\section{Uses of selected wastes}

The nature of construction and demolition waste and energy by-products, as well as their chemical, mineralogical, physical, and other properties, places some restrictions on their application in the building industry (see Table 1). Pursuant to REACH (stands for Registration, Evaluation, Authorization and Restriction of Chemical Substances (EU)) and other legal documents of the EU, meeting the prescribed rules is critical and without due registration it would be impossible to operate with the material at all. This concerns e.g. the use of construction and demolition waste and energy by-products in cement, concrete, porous aggregates, porous masonry blocks, their use as aggregate in road construction, as a building or filler material, during mining operations, as mineral fillers, etc. [20-27].

However, the current industry produces new kinds of wastes, for the re-use of which there is no official methodology, clear standardized requirements, or other specifications. Another goal of this paper was therefore to present new and non-traditional uses of the best-scoring construction and demolition waste and energy by-products - waste glass from QS solar panels, high-temperature filter fly ash, and recycled concrete.

\subsection{Waste glass from solar panels}

The best solar panels of today are expected to have a service life (the end of which is defined as a $20 \%$ decrease in performance) of 30 to 40 years at most. However, the most common reason for discarding a solar panel is currently mechanical damage it may have suffered during transport or installation. The main problem in lower-quality panels tends to be delamination - a disintegration of the panel's sandwich structure due to temperature and UV light. The PV Cycle was designed for solar panel recycling. This is a pan-European effort of solar panel manufacturers and suppliers built on voluntary responsibility for the product

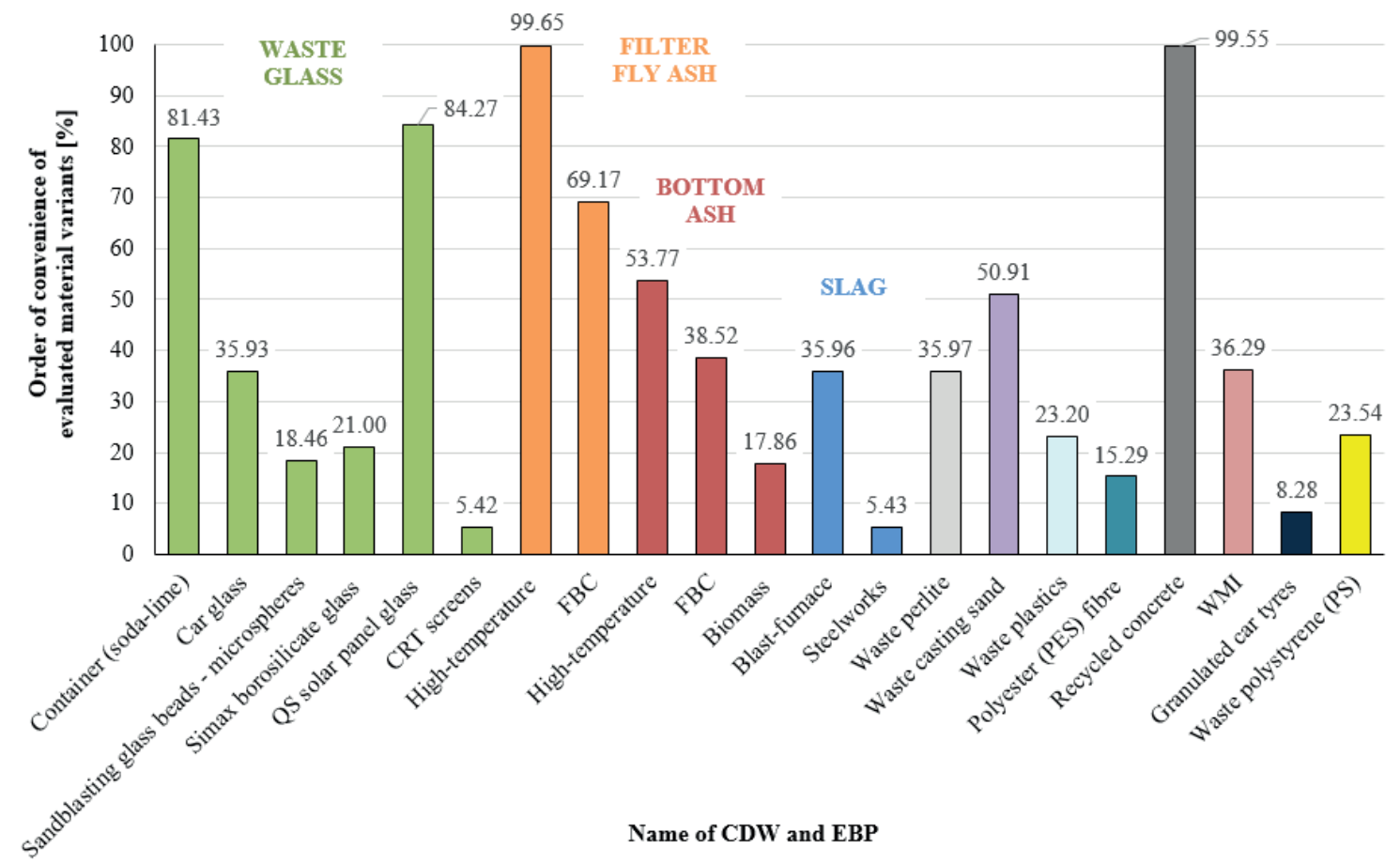

Fig. 4 Wastes which were found to be the most suitable for re-use in civil engineering 
through the whole of its service life. Most of the solar panel mass is glass (60-70\%) and aluminum frame (around $20 \%$ ), while in slim solar panels, glass and aluminum make up over $95 \%$. The year 2010 saw the highest number of panels installed, specifically 160000 tons of panels, which are expected to complete their service life in 2040 [28].

Before the glass from defunct solar panels can be used, their aluminum frame must be removed. The top layer of glass can be easily separated from the polymer back sheet, and later milled down to the desired fraction in a ball mill (Fig. 5 (a)). The density of this glass is around $2500 \mathrm{~kg} \cdot \mathrm{m}^{-3}$ and loss on ignition $\left(1100{ }^{\circ} \mathrm{C}\right)$ is around $0.65 \%$ of dry mass. As regards chemical composition, the content of $\mathrm{SiO}_{2}$ is around $71 \%, \mathrm{CaO}$ is $8.45 \%, \mathrm{Na}_{2} \mathrm{O}$ is $12 \%$, plus a minor amount of other oxides. Once sufficiently pretreated, this waste glass was successfully used as filler in polymer, epoxy-based reprofiling mortars (Fig. 5 (b)). The material performed well in resisting the weather conditions in the Czech Republic.

\subsection{Filter fly ash}

The uses of filter fly ash vary depending on its chemical, mineralogical, and physical properties. These properties depend on the type of power plant, coal origin, and the type of coal lock. The principal requirement for application is consistent quality. In this regard, the residues from black coal combustion are better than those from brown coal, whose composition tends to be less consistent [29].

Although there are several new technologies that make coal combustion eco-friendlier by effectively reducing $\mathrm{NO}_{x}$ emissions, many thermal power plants and incinerators choose SNCR (selective non-catalytic reduction), mainly because of financial reasons. During this process the fly ash comes in direct contact with the medium being sprayed into the chamber. Such ash then usually contains high amounts of ammonium salts. With high $\mathrm{NH}_{3}$ content it is difficult to use such a fly ash as concrete filler or as partial cement substitute, and different uses should
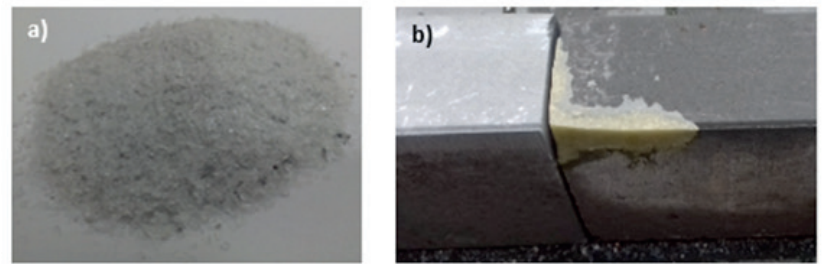

Fig. 5 a) Waste glass from solar panels milled to a fraction of $0-1.5$ $\mathrm{mm}, \mathrm{b})$ Kerb reprofiled with a mortar containing $75 \%$ of waste glass from QS solar panels after 400 days of exposure to the weather conditions
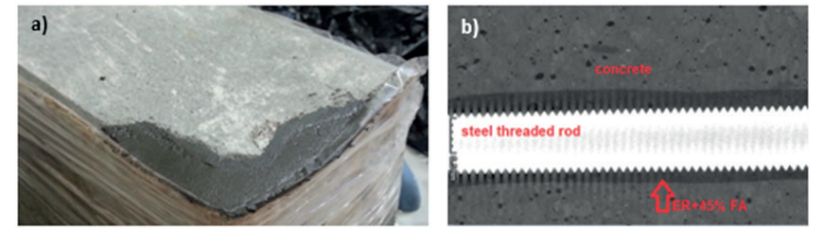

Fig. 6 a) Kerb reprofiled with a mortar containing $60 \%$ of fly ash contaminated by flue gas denitrification; picture after 400 days of exposure to weather conditions, b) CT image showing the quality of anchoring of a threaded rod using a new anchoring mortar with a $45 \%$ content of fly ash contaminated by flue gas denitrification

therefore be sought. The standard EN 450 defines conditions under which fly ash can still be used in concrete as an active addition. It appears that its best use is as filler in polymer repair and anchor mortars. Tests have shown that polymer repair mortars perform well with $60 \%$ filler content, and a proof-of-concept concrete kerb reprofilation was performed (see Fig. 6(a)). The optimum content of this filler in polymer grouting and anchoring mortars appeared to be $45 \%$; where even after a pull-out strength test, load of $100 \mathrm{kN}$, the bond between the mortar and the substrate remained undamaged (see Fig. 6(b)). Even fly ash that has been contaminated due to flue gas denitrification can thus be successfully used as filler in repair mortars instead of primary fillers commonly used today, while even improving the properties of the mortar. Using this fly ash is therefore economical and eco-friendly.

\subsection{Recycled concrete}

Waste concrete is currently recycled by being crushed and added to new concrete as aggregate. However, Xiao et al. [30] stated that this method only utilizes the coarse fraction $(>1 \mathrm{~mm})$. The finer fraction $(<1 \mathrm{~mm})$ currently has no large-scale use. This is why there was the effort to investigate new uses of this material in cement composite manufacturing. This entails, for instance, using a thermally activated recycled concrete as a binder replacement [31] or as a mixture for cement manufacturing explored by Schoon et al. [32]. It can also be used in geopolymer binders [33]. It should be noted, however, that these methods consume a lot of energy and produce a large amount of $\mathrm{CO} 2$ emissions. This is why the fine fraction of recycled concrete was not modified thermally but mechanically by high-speed milling [26]. In economic terms, high-speed milling may consume large amounts of energy, but the absence of high temperatures still makes it viable enough.

The principle of mechanical activation of recycled concrete is that the milling exposes particles of unhydrated clinker, whose amount depends on the type of cement and 
age of the concrete. In general, the unhydrated clinker makes up 10 to $20 \mathrm{wt}$. \% [34]. If the unhydrated particles have been correctly activated, they can replace a portion of cement in new composites. The rest consists of inert particles, which become micro-filler. The re-use of recycled concrete saves cement and natural fillers [35].

\section{Conclusions}

The aim of this paper was to provide an advanced study for discovering new, non-traditional uses of selected kinds of construction and demolition waste. The study used an optimizing multi criteria calculation, which was based on a specification of the wastes, drawing on existing EU legislation. The main criteria entering the calculation, which then determined the possibilities of construction and demolition waste and energy by-products use, were the degree of pre-treatment, difficulty of pre-treatment, availability, cumulative amount, parameter dispersion, and spectrum of application. The outcome of the multi criteria calculation is a selection of the waste for future use in civil engineering. They had the highest total of the products of transformed criteria values, weights and order of viability of all variants. The criterion with the greatest weight was cumulative amount followed by spectrum of application. The results of the optimization calculation show that the most suitable construction and demolition waste and energy

\section{References}

[1] The European Parliamen and the Council of the European Union "Directive 2008/98/EC of the European Parliament and of the Council of 19 November 2008 on waste and repealing certain Directives (Text with EEA relevance)", Official Journal of the European Union, 15(034), pp. 99-126, 2008. [online] Available at: http://data.europa. eu/eli/dir/2008/98/oj [Accessed: 15 October 2019]

[2] Gálvez-Martos, J.-L., Styles, D., Schoenberger, H., ZeschmarLahl, B. "Construction and demolition waste best management practice in Europe", Resources, Conservation and Recycling, 136, pp. 166-178, 2018.

https://doi.org/10.1016/j.resconrec.2018.04.016

[3] Menegaki, M., Damigos, D. "A review on current situation and challenges of construction and demolition waste management", Current Opinion in Green and Sustainable Chemistry, 13, pp. 8-15, 2018. https://doi.org/10.1016/j.cogsc.2018.02.010

[4] Pacheco-Torgal, F., Tam, V. W. Y., Labrincha, J. A., Ding, Y., de Brito, J. (eds.) "Handbook of Recycled Concrete and Demolition Waste", Woodhead Publishing, Abington Hall, Cambridge, UK, 2013.

[5] European Commission "Circular Economy - Implementation of the Circular Economy Action Plan", [online] Available at: https://ec.europa.eu/environment/circular-economy/index_en.htm [Accessed: 15 October 2019] by-products are waste glass from QS-type solar panels, high-temperature fly ash, and recycled concrete. The filter fly ash received the highest preference of $99.65 \%$, second highest was recycled concrete with $99.55 \%$ and third was waste glass from QS solar panels with $84.27 \%$.

It should be noted that most construction and demolition waste and energy by-products have potential for future use. Regarding REACH and other EU legislation, however, they must always meet the prescribed requirements, which is critical for the ability to operate with the material. The results show that the chosen waste with a score of $70 \%$ (order of viability of the material variants) are fully applicable e.g. in cement, concrete, porous aggregate and masonry blocks, and as aggregate in road construction, as a building or filler material, in mining, or as mineral fillers. The wastes do not necessarily require treatment to be re-used. However, as regards wastes with a score of $40-70 \%$, it is necessary to conduct a detailed technological and financial investigation into their properties and propose treatments where needed.

\section{Acknowledgement}

This paper has been worked out under the project No. LO1408 "AdMaS UP - Advanced Materials, Structures and Technologies", supported by Ministry of Education, Youth and Sports under the "National Sustainability Programme I".

[6] European Commission "Communication from the commission to the European parliament, the council, the European economic and social committee and the committee of the regions: Closing the loop - An EU action plan for the Circular Economy", [online] Available at: https://eur-lex.europa.eu/legal-content/EN/ ALL/?uri=CELEX\%3A52015DC0614 [Accessed: 17 October 2019]

[7] de Magalhães, R. F., de Moura Ferreira Danilevicz, Â., Saurin, T. A. "Reducing construction waste: A study of urban infrastructure projects", Waste Management, 67, pp. 265-277, 2017. https://doi.org/10.1016/j.wasman.2017.05.025

[8] Zeller, V., Towa, E., Degrez, M., Achten, W. M. J. "Urban waste flows and their potential for a circular economy model at city-region level", Waste Management, 83, pp. 83-94, 2019. https://doi.org/10.1016/j.wasman.2018.10.034

[9] Bovea, M. D., Powell, J. C. "Developments in life cycle assessment applied to evaluate the environmental performance of construction and demolition wastes", Waste Management, 50, pp. 151-172, 2016. https://doi.org/10.1016/j.wasman.2016.01.036

[10] Coelho, A., de Brito, J. "Influence of construction and demolition waste management on the environmental impact of buildings", Waste Management, 32(3), pp. 532-541, 2012. https://doi.org/10.1016/j.wasman.2011.11.011 
[11] European Commission "Communication from the commission to the European parliament and the council: Strategy for the sustainable competitiveness of the construction sector and its enterprises", [online] Available at: https://eur-lex.europa.eu/legal-content/EN/ TXT/?uri=CELEX\%3A52012DC0433 [Accessed: 17 October 2019]

[12] European Commission "Communication from the commission to the European parliament and the council: the European economic and social committee and the committee of the regions: On resource efficiency opportunities in the building sector", [online] Available at: https://eur-lex.europa.eu/legal-content/en/ TXT/?uri=CELEX\%3A52014DC0445 [Accessed: 17 October 2019]

[13] European Commission "Best environmental management practice", [online] Available at: https://ec.europa.eu/jrc/en/research-topic/bestenvironmental-management-practice [Accessed: 12 October 2019]

[14] Bilsen, V., Kretz, D., Padilla, P., Van Acoleyen, M., Van Ostaeyen, J., Izdebska, O., Hansen, M. E., Bergmans, J., Szuppinger, P. "Development and implementation of initiatives fostering investment and innovation in construction and demolition waste recycling infrastructure", [pdf] European Commission, Brussels, Available at: https://ec.europa.eu/environment/waste/studies/pdf/CDW\%20infrastructure\%20study.pdf [Accessed: 12 October 2019]

[15] Giorgi, S., Lavagna, M., Campioli, A. "Guidelines for Effective and Sustainable Recycling of Construction and Demolition Waste", In: Benetto, E., Gericke, K., Guiton, M. (eds.) Designing Sustainable Technologies, Products and Policies, Springer, Cham, Switzerland, 2018, pp. 211-221.

https://doi.org/10.1007/978-3-319-66981-6_24

[16] Eurostat "Waste statistics", [online] Available at: https://ec.europa. eu/eurostat/statistics-explained/index.php?title=Waste_statistics [Accessed: 22 September 2019]

[17] Kylili, A., Fokaides, P. A. "Policy trends for the sustainability assessment of construction materials: A review", Sustainable Cities and Society, 35, pp. 280-288, 2017.

https://doi.org/10.1016/j.scs.2017.08.013

[18] Bakchan, A., Faust, K. M. "Construction waste generation estimates of institutional building projects: Leveraging waste hauling tickets", Waste Management, 87, pp. 301-312, 2019.

https://doi.org/10.1016/j.wasman.2019.02.024

[19] Neto, R. O., Gastineau, P., Cazacliu, B. G., Le Guen, L., Paranhos, R. S., Petter, C. O. "An economic analysis of the processing technologies in CDW recycling platforms", Waste Management, 60, pp. 277-289, 2017.

https://doi.org/10.1016/j.wasman.2016.08.011

[20] European Standard "EN 197-1 Cement - Part 1: Composition, specifications and conformity criteria for common cements", CEN, Brussels, Belgium, 2012.

[21] European Standard "EN 450-1 Fly ash for concrete - Part 1: Definition, specifications and conformity criteria", CEN, Brussels, Belgium, 2013.

[22] European Standard "EN 450-2 Fly ash for concrete - Part 2: Conformity evaluation", CEN, Brussels, Belgium, 2005.

[23] European Standard "EN 13108-21 ED.2 Bituminous mixtures Material specifications - Part 21: Factory Production Control", CEN, Brussels, Belgium, 2017.
[24] Mohajerani, A., Vajna, J., Cheung, T., Kurmus, H., Arulrajah, A., Horpibulsuk, S. "Practical recycling applications of crushed waste glass in construction materials: A review", Construction and Building Materials, 156, pp. 443-467, 2017. https://doi.org/10.1016/j.conbuildmat.2017.09.005

[25] Cristelo, N., Fernández-Jiménez, A., Vieira, C., Miranda, T., Palomo, Á. "Stabilisation of construction and demolition waste with a high fines content using alkali activated fly ash", Construction and Building Materials, 170, pp. 26-39, 2018. https://doi.org/10.1016/j.conbuildmat.2018.03.057

[26] Akhtar, A., Sarmah, A. K. "Construction and demolition waste generation and properties of recycled aggregate concrete: A global perspective", Journal of Cleaner Production, 186, pp. 262-281, 2018. https://doi.org/10.1016/j.jclepro.2018.03.085

[27] Jiménez-Rivero, A., García-Navarro, J. "Exploring factors influencing post-consumer gypsum recycling and landfilling in the European Union", Resources, Conservation and Recycling, 116, pp. 116-123, 2017.

https://doi.org/10.1016/j.resconrec.2016.09.014

[28] Bechník, B., Poruba, A. "Recycling of photovoltaic panels on the end of life", [online] Available at: https://oze.tzb-info.cz/fotovoltaika/7868-recyklace-fotovoltaickych-panelu-na-konci-zivotnosti [Accessed: 12 October 2019] (in Czech)

[29] European Environment Agency "Directive 2001/80/EC of the European Parliament and of the Council of 23 October 2001 on the limitation of emissions of certain pollutants into the air from large combustion plants", [online] Available at: https://www.eea.europa. eu/policy-documents/directive-2001-80-ec-large [Accessed: 22 September 2019]

[30] Xiao, J., Li, W., Fan, Y., Huang, X. "An overview of study on recycled aggregate concrete in China (1996-2011)", Construction and Building Materials, 31, pp. 364-383, 2012. https://doi.org/10.1016/j.conbuildmat.2011.12.074

[31] Shui, Z., Xuan, D., Wan, H., Cao, B. "Rehydration reactivity of recycled mortar from concrete waste experienced to thermal treatment", Construction and Building Materials, 22(8), pp. 1723-1729, 2008. https://doi.org/10.1016/j.conbuildmat.2007.05.012

[32] Schoon, J., der Heyden, L. V., Eloy, P., Gaigneux, E. M., De Buysser, K., Van Driessche, I., De Belie, N. "Waste fibrecement: An interesting alternative raw material for a sustainable Portland clinker production", Construction and Building Materials, 36, pp. 391-403, 2012. https://doi.org/10.1016/j.conbuildmat.2012.04.095

[33] Ahmari, S., Ren, X., Toufigh, V., Zhang, L. "Production of geopolymeric binder from blended waste concrete powder and fly ash", Construction and Building Materials, 35, pp. 718-729, 2012. https://doi.org/10.1016/j.conbuildmat.2012.04.044

[34] Topič, J., Prošek, Z., Fládr, J., Tesárek, P. "Influence of fineness of recycled concrete powder on the heat evolution and influence of its amount on mechanical-physical properties of cement paste", Waste Forum, 2, pp. 268-274, 2018. (in Czech)

[35] Prošek, Z., Topič, J., Dureje, J., Trejbal, J. "Comparison between the impact of micronized waste concrete and marble additions on mechanical properties of cementitious pastes", Waste Forum, 2, pp. 262-267, 2018. (in Czech) 